\title{
A Very Strong Enhancer Is Located Upstream of an Immediate Early Gene of Human Cytomegalovirus
}

\author{
Michael Boshart, $¥$ Frank Weber, $†$ Gerhard Jahn," \\ Karoline Dorsch-Häsler, ${ }^{\dagger}$ Bernhard Fleckenstein, ${ }^{*}$ \\ and Walter Schaffner ${ }^{\dagger}$ \\ * Institut für Klinische Virologie der \\ Universität Erlangen-Nürnberg \\ D-8520 Erlangen \\ Federal Republic of Germany \\ † Institut für Molekularbiologie II der Universität Zürich \\ Hönggerberg, $\mathrm{CH}-8093$ Zürich \\ Switzerland \\ ‡Present address: Institut für Zell- und Tumorbiologie \\ Deutsches Krebsforschungszentrum \\ D-6900 Heidelberg \\ Federal Republic of Germany
}

\section{Summary}

A strong transcription enhancer was identified in the genomic DNA (235 kb) of human cytomegalovirus (HCMV), a ubiquitous and severe pathogen of the herpesvirus group. Cotransfection of enhancerless SV40 DNA with randomly fragmented HCMV DNA yielded two SV40-HCMV recombinant viruses that had incorporated overlapping segments of HCMV DNA to substitute for the missing SV40 enhancer. Within HCMV, these enhancer sequences are located upstream of the transcription initiation site of the major immediate-early gene, between nucleotides -118 and -524. Deletion studies with the HCMV enhancer, which harbors a variety of repeated sequence motifs, show that different subsets of this enhancer can substitute for the SV40 enhancer. The HCMV enhancer, which seems to have little cell type or species preference, is severalfold more active than the SV40 enhancer. It is the strongest enhancer we have analyzed so far, a property that makes it a useful component of eukaryotic expression vectors.

\section{Introduction}

Human cytomegalovirus (HCMV), a member of the herpes group, is a ubiquitous human pathogen that causes, among many other syndromes, multiple forms of embryopathies and fetopathies as a consequence of prenatal infection (Weller, 1971; Stagno et al., 1982). It is increasingly recognized as a cause of severe pneumonitis and septicemia in immunocompromised individuals such as tumor patients undergoing aggressive chemotherapy or persons affected by the acquired immunodeficiency syndrome (AIDS). HCMV has a genome of linear doublestranded DNA of about $235 \mathrm{~kb}$; it consists of a long unique region $\left(U_{L}\right)$ and a short unique region $\left(U_{S}\right)$, each flanked by a pair of inverted repeats (LaFemina and Hayward, 1980; Ebeling et al., 1983). Each segment can be oriented in either direction, resulting in four isomeric forms of virion DNA (Fleckenstein et al., 1982). During the infection cycle, transcription of viral genes occurs in three phases (reviewed by Stinski, 1983). In the immediate-early (IE) phase, a small set of viral genes are expressed independent of preceding viral protein synthesis. The IE proteins are thought to possess primarily regulatory functions; they are required for initiation of the early transcriptional phase, which is followed by DNA replication and synthesis of the late gene products (DeMarchi, 1981; Wathen and Stinski, 1982; McDonough and Spector, 1983). At least four IE genes are localized essentially within the Hind III E-fragment contained in the $\mathrm{U}_{\mathrm{L}}$ region (Jahn et al., 1984a). The most abundant IE RNA is a polyadenylated transcript of $1.9 \mathrm{~kb}$ that encodes a $72 \mathrm{kd}$ phosphoprotein (Stinski et al., 1983). The strength of the corresponding IE promoter (A. Grässmann, G. Jahn, and B. Fleckenstein, unpublished) led us to ask if it is under the control of an enhancer-like element, akin to the early promoters of some smaller DNA viruses.

Enhancers are cis-acting elements of DNA that stimulate transcription of adjacent genes by RNA polymerase II, in either orientation, and over distances up to several kilobase pairs, even from a position downstream of the transcribed region (Banerii et al., 1981; de Villiers and Schaffner, 1981; Moreau et al., 1981). Viral enhancers were originally identified in SV40 and polyoma virus as "far-upstream" promoter elements required for efficient early transcription (Benoist and Chambon, 1981; Gruss et al., 1981; Fromm and Berg, 1982; Tyndall et al., 1981). More recently, enhancer elements have been found in a variety of other viruses (reviewed in Gluzman and Shenk, 1983; Gruss, 1984; Picard, 1985). Some enhancers, for example from polyoma virus and Moloney murine sarcoma virus, show a host cell preference and thus contribute to the host range of the virus (de Villiers et al., 1982; Laimins et al., 1982). Others, like the SV40 enhancer, are active in a wide variety of cell types from many species (de Villiers et al., 1982; Neuhaus et al., 1984). A sequence with properties of an enhancer has also been identified upstream of the promoter for IE mRNA 3 of herpes simplex virus type 1 (Lang et al., 1984; Preston and Tannahill, 1984). Enhancers with a strict cell type specificity have been found in association with cellular genes, notably immunoglobulin genes (Banerji et al., 1983; Gillies et al., 1983; Neuberger, 1983; Queen and Baltimore, 1983; Picard and Schaffner, 1984).

Heterologous enhancers have been shown to substitute for the enhancer of SV4O or polyoma virus, allowing T antigen expression and viral DNA replication (de Villiers et al., 1982; Levinson et al., 1982; Lusky et al., 1983; Fried et al., 1983). This has allowed us to develop a method for detection of enhancer elements in large genomes by an "enhancer trap" assay. Linearized SV40 DNA lacking its own enhancer is cotransfected with short randomly fragmented heterologous DNA into permissive cell cultures. Incorporation of foreign DNA with enhancer function can give rise to lytically growing SV40-type recombinants (Weber et al., 1984). We show that, by applying the de- 


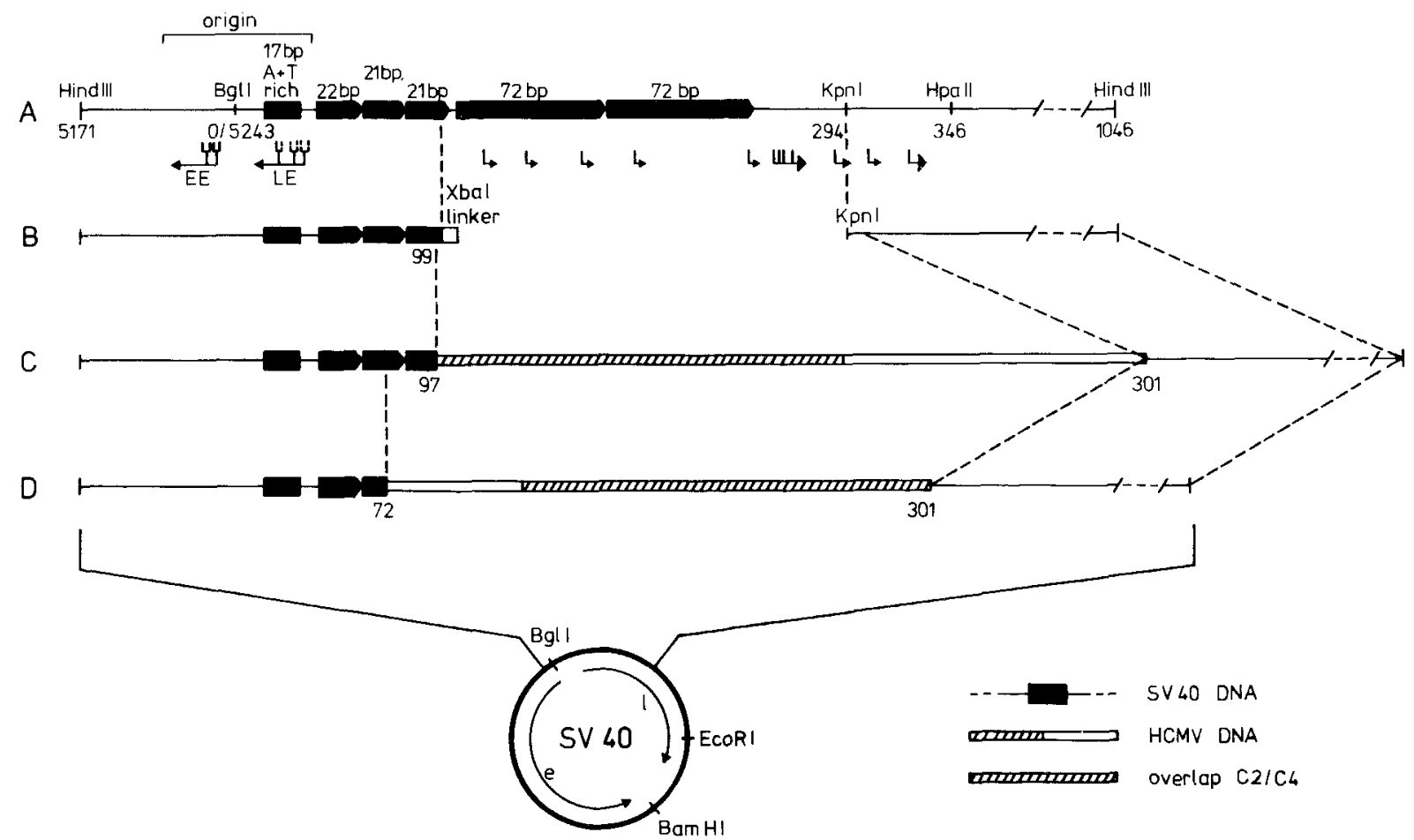

Figure 1. Schematic Maps of the SV40-HCMV Recombinants Generated by the Enhancer Trap Approach

The Hind III C-fragments of the respective viral molecules spanning the origin of DNA replication are expanded.

(A) SV40 wild-type virus genome. The two $72 \mathrm{bp}$ direct repeats and the two $21 \mathrm{bp}$ direct repeats with the related 22 bp sequence are indicated by

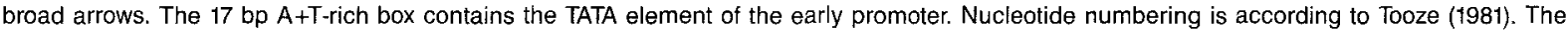
positions of the early-early (EE), late-early (LE), and late mRNA initiation sites are indicated by arrows (Everett et al., 1983; Contreras et al., 1982). (B) The SV40 enhancer trap (Weber et al., 1984). The enhancer deletion between the Xba I linker at position 99 and the Kpn I cleavage site in the enhancer trap clone pET-1 is indicated. The Xba I linker mutant of SV40, a gift from Y. Gluzman (Cold Spring Harbor), was cloned into the plasmid vector pJC-1. For enhancer trap experiments, the viral DNA was released from the plasmid by Kpn I and Xba I digestion.

(C) Recombinant C2 was obtained from a cotransfection of enhancer trap DNA with sonicated Pst I m-fragment of HCMV (see Figure 2). The insertion of $341 \mathrm{bp}$ of foreign DNA between SV40 positions 97 and 301 is indicated. A few bases were deleted from the Kpn I and Xba I ends of the SV40 enhancer trap DNA. Of the inserted DN'A 196 bp are overlapping with the HCMV DNA segment contained in recombinant C4, as indicated by hatching.

(D) Recombinant $\mathrm{C} 4$ obtained from the same experiment as recombinant C2. Of foreign DNA 262 bp are inserted between SV40 positions 72 and 301. At the left junction the HCMV DNA was probably integrated by homologous recombination into the $21 \mathrm{bp}$ region of SV40, resulting in a $27 \mathrm{bp}$ deletion of SV40 sequences (see also text).

leted SV40 genome as a trap, a strong enhancer DNA sequence is identified upstream of the dominant IE promoter of HCMV. The cytomegalovirus enhancer was sequenced and functionally characterized by linkage to a heterologous gene (rabbit $\beta$-globin) and by deletion analysis.

\section{Results}

\section{Detection of HCMV Sequences Substituting for the 72 Bp Repeat of SV40}

The enhancerless SV40 genome, lacking the entire $72 \mathrm{bp}$ repeat region and some adjacent sequences (Figure 1), was prepared by cleavage with both $\mathrm{Xba} I$ and $\mathrm{Kpn} \mathrm{I}$, thus excising the plasmid vector and linearizing the SV40 at the deletion endpoints (Weber et al., 1984). This "enhancer trap" was cotransfected with randomly sheared ( $\sim 300 \mathrm{bp})$ DNA fragments of HCMV strain AD169. DNA from the Pst I $\mathrm{m}$-segment $(2.1 \mathrm{~kb})$, which spans the promoter region of the dominant (1.9 kb) IE mRNA (Jahn et al., 1984a, 1984b), was found to restore SV40 growth most efficiently. Such a viral DNA preparation was cloned into a plasmid vector.

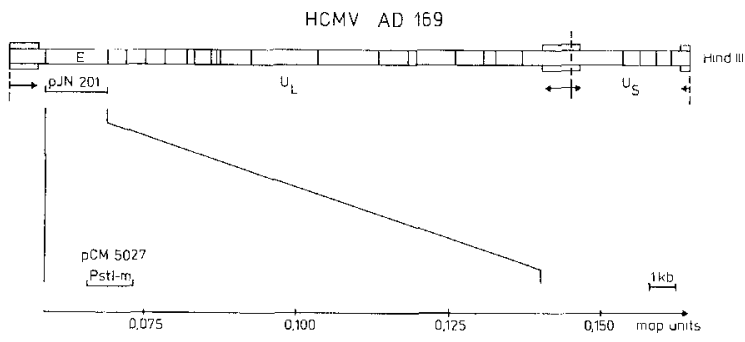

Figure 2. The 235 Kilobase Pair Genome of Human Cytomegalovirus Strain AD169 in the Prototype Orientation

The terminal inverted repeats flanking the long unique $\left(U_{L}\right)$ and short unique $\left(U_{S}\right)$ regions of the genome are boxed and indicated by arrows. Hind III cleavage sites are shown by vertical lines. The Hind III E-segment (clone pJN20t, $21.5 \mathrm{~kb}$ ) encompassing most of the immediate early (IE) region is magnified to demonstrate the map position of the Pst I m-segment (clone pCM5027, $2.1 \mathrm{~kb}$ ) (Greenaway et al., 1982; Jahn et al., 1984a).

Four individual viral clones were reclaimed from the plasmid and once more transfected into CV1 cells. In this way, defective viruses that require trans-complementation (two out of the four) were excluded. The two resulting viable 
A - 737 aAtcaAtat

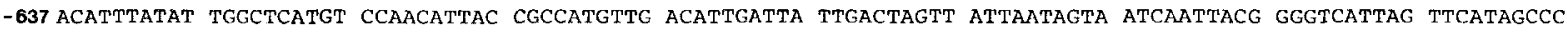

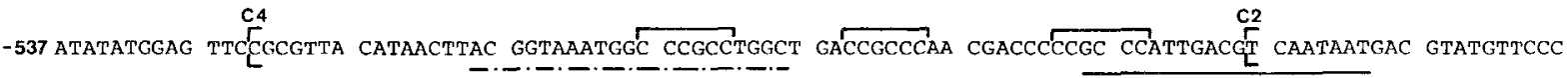
-437 ATAGTAACGC CAATAGGGAC TTTCCATTGA CGTCAATGg TGGAGTATTT ACGGTAAACT GCCCACTTGG CAGTACATCA AGTGTATCAT ATGCCAAGTA

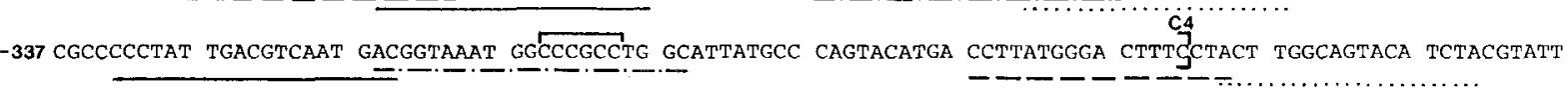

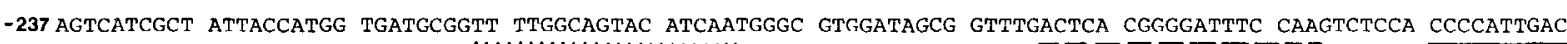

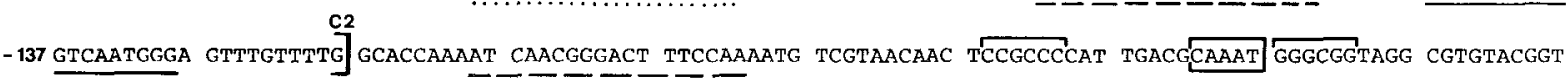

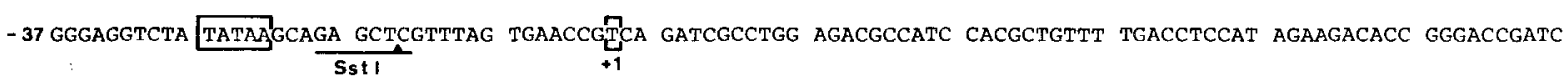

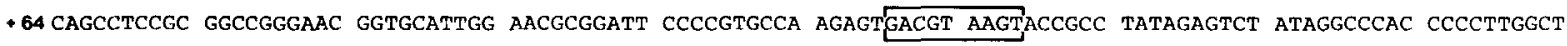
+164 TCtTatgcat gCtatactgt TTTTGgCTTG

B $17 \mathrm{bp}$ repect
$18 \mathrm{bp}$ repeat
$19 \mathrm{bp}$ repedt
$21 \mathrm{bp}$ repeat
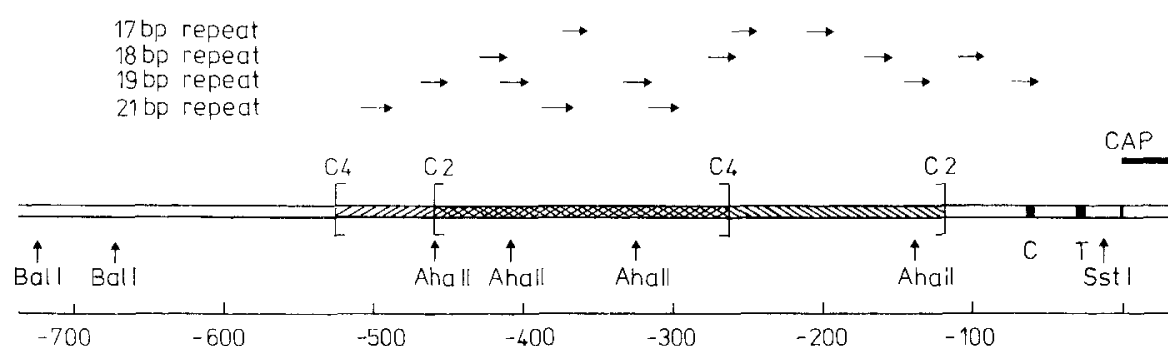

$1.9 \mathrm{~kb}$ mPNA

Figure 3. Enhancer/Promoter Region of the Major IE Gene of HCMV

(A) Nucleotide sequence of the HCMV enhancer and flanking DNA. The 341 bp of HCMV DNA contained in the SV4O-HCMV recombinant C2 and the 262 bp contained in recombinant $C 4$ are indicated by brackets. Four classes of imperfect direct repeats are underlined: $-\cdot-\cdot \cdot-21$ bp repeat; $-19 \mathrm{bp}$ repeat; - - - $18 \mathrm{bp}$ repeat; . . . 17 bp repeat. The transcription initiation site of the $1.9 \mathrm{~kb}$ IE transcript has been determined for HCMV strain Towne by Stenberg et al. (1984) using St nuclease mapping. The cap of the $1.9 \mathrm{~kb}$ IE RNA is most likely located at an identical position in HCMV strain AD169 (see text). Cap site, TATA box, a possible CAAT box, and a sequence closely related to the splice donor consensus sequence (Mount, 1982) are boxed. Furthermore, the GC-rich hexanucleotides 5'-CCGCCC-3', 5'-CCCGCC-3', and 5'-GGGCGG-3' are indicated.

(B) Schematic presentation of the sequence shown in (A). The enhancer region as defined by the recombinant viruses $\mathrm{C} 2$ and $\mathrm{C} 4$ extends between nucleotides -118 and -524 . The possible CAAT box (C), the TATA box (T), and the splice donor signal (S) are indicated. The location of the cap and first exon of the $1.9 \mathrm{~kb}$ IE mRNA in HCMV strain Towne is included as determined with S1 nuclease mapping by Stenberg et al. (1984). The elements of the four classes of imperfect direct repeats are represented by arrows. The clustering of the different repeat structures in the enhancer region is obvious. The Aha If restriction sites within the palindromic 19 bp sequences were used for construction of a set of deletion mutants (see Figure 5).

HCMV-SV40 recombinants, designated $\mathrm{C} 2$ and $\mathrm{C} 4$, were found to contain HCMV sequences substituting for the SV40 72 bp repeat (see below). Similar HCMV DNA segments were incorporated into the SV40 enhancer trap if the much larger Hind III E-fragment $(21.5 \mathrm{~kb})$, which contains the Pst I m-fragment (see Figure 2), was sheared and used for cotransfection (not shown).

\section{Nucleotide Sequence of the HCMV Enhancer and Localization Relative to the Dominant Immediate-Early Gene of HCMV}

The recombinant viruses $\mathrm{C} 2$ and $\mathrm{C} 4$ were both analyzed by DNA sequencing. $\mathrm{C} 2$ had been created by ligation of a 341 bp segment of HCMV DNA between the ends of a linear enhancer trap molecule (Figures 1B, 1C). A few bases were deleted from the $\mathrm{Kpn} I$ and $\mathrm{Xba} I$ ends of the SV40 enhancer trap DNA, presumably as a result of exonucleolytic degradation prior to ligation within the transfected cell. The recombinant virus $\mathrm{C} 4$ arose by integration of a 262 bp segment of HCMV DNA into enhancer trap
DNA (Figure 1D). On one side, joining was by the usual end-to-end ligation; on the other side, joining occurred by recombination via a 6 bp homology between HCMV (nucleotides -531 to -526 ) and SV40 (nucleotides 67-72) (Figure 3). This resulted in a deletion of $27 \mathrm{bp}$ of SV40 DNA (nucleotides 73-99), affecting both 21 bp repeats of the SV40 early promoter. Deletion of these $21 \mathrm{bp}$ repeats is compatible with SV40 replication (Hartzell et al., 1983). In previous experiments we observed in vivo recombination at a $5 \mathrm{bp}$ homology between enhancer trap and enhancer fragment (Weber et al., 1984). Such homologous recombination events occur more frequently with linear substrate DNAs than with circular DNAs (Lin et al., 1984; P. Pfeiffer, J. de Villiers, and W. Schaffner, unpublished).

The HCMV sequences in recombinants $\mathrm{C} 2$ and $\mathrm{C} 4$ overlap by 196 bp (Figures 1, 3). For comparison, a 930 bp segment of the Pst I m-fragment from HCMV strain AD169 DNA was sequenced (Figure 3). The $341 \mathrm{bp}$, as well as the 262 bp HCMV DNA sequences contained in recombinants $\mathrm{C} 2$ and $\mathrm{C} 4$, were both identical to the 
genomic HCMV virion sequence. Also, in the flanking SV40 DNA no deviation from the SV40 wild-type sequence occurred. In recombinants $\mathrm{C} 2$ and $\mathrm{C} 4$, therefore, no secondary sequence rearrangements appear to have taken place.

Promoter organization and the $5^{\prime}$ end of the $1.9 \mathrm{~kb} \mathrm{IE}$ mRNA of HCMV strain AD169 (M. Boshart, G. Jahn, and B. Fleckenstein, unpublished data) appear very similar, if not identical, to the corresponding structures of strain Towne that have been analyzed recently by nucleotide sequencing and S1 mapping (Thomsen et al., 1984). Comparison of the sequences of HCMV strains AD169 and Towne revealed identity for the short RNA leader and $97 \%$ homology for $491 \mathrm{bp}$ upstream of the $5^{\prime}$ terminus of the 1.9 kb mRNA. The HCMV DNA segment contained within the recombinant virus $\mathrm{C} 2$ is therefore between nucleotides -118 and -458 upstream of the cap site, and the segment contained in recombinant $\mathrm{C} 4$ represents nucleotides -263 to -524 (Figure 3).

\section{Growth Properties of SV40-HCMV Recombinant Viruses}

In several passages on CV1 cells, recombinant viruses C2 and $\mathrm{C} 4$ grew about as well as wild-type SV40 (Table 1 and unpublished data). The viral host range was not obviously changed by the substitution of the HCMV enhancer for the SV40 enhancer. Recombinants $\mathrm{C} 2$ and $\mathrm{C} 4$ both were unable to grow lytically on all other cells tested, including human foreskin fibroblast cells used as host for HCMV growth and human HeLa, human hepatoma, and mouse fibroblast cells. In mouse cells, and even in frog (Xenopus laevis) kidney cells, transfection with C4 DNA yielded a 3-fold greater number of T antigen positive cells than SV40 DNA (data not shown). This indicates that the HCMV enhancer has a broad host range, similar to the host range of the SV40 enhancer, and that it is stronger than the SV40 enhancer in nonprimate cells, as it is in human HeLa cells (see below).

\section{$\beta$-Globin Transcription Is Enhanced by the Trapped HCMV-DNA}

The substitution of the 72 bp repeat of SV40 could formally be achieved by selection with the enhancer trap for strong regulatory sequences other than classical enhancer elements. Thus, we wanted to determine whether or not the HCMV sequences identified by the enhancer-trap assay could stimulate transcription of a linked heterologous gene over long distances, in either orientation, and from a position downstream of the gene.

The Hind III C-fragments of both recombinant viruses $\mathrm{C} 2$ and $\mathrm{C} 4$ (see Figure 1) and the Pst I m-fragment of HCMV were cloned in either orientation downstream of the rabbit $\beta$-globin gene (Figure 4A). Enhancement of $\beta$-globin transcription was quantitated by $S 1$ nuclease analysis of cytoplasmic RNA after transient expression in HeLa cells (see Figure 4B). All constructs were assayed under standardized conditions together with analogous constructs having the SV40 enhancer inserted at the same position relative to the $\beta$-globin gene. Figure $4 \mathrm{C}$ shows that the HCMV sequences from recombinants $C 2$

\begin{tabular}{|c|c|c|c|}
\hline \multirow[b]{2}{*}{ DNA Clone $e^{a}$} & \multirow{2}{*}{$\begin{array}{l}\% \text { of Cells } \\
\text { with Nuclear } \\
\mathrm{T} \text { Antigen } \\
\text { Fluorescence } \\
\text { Experiment } 1\end{array}$} & \multicolumn{2}{|c|}{$\begin{array}{l}\text { Time from Transfection } \\
\text { to Lysis of } \geqslant 50 \% \text { of } \\
\text { Cells (in days) }\end{array}$} \\
\hline & & Experiment 2 & Experiment 3 \\
\hline $\mathrm{C} 2$ (HCMV) & $6.9 \%$ & 12 & 17 \\
\hline $\mathrm{C} 4^{\mathrm{c}}$ & $5.8 \%$ & 12 & 17 \\
\hline \multicolumn{4}{|l|}{ Deletion mutants } \\
\hline 1 & $5.4 \%$ & 12 & 19 \\
\hline 2 & $6.2 \%$ & 14 & 19 \\
\hline 3 & $4.0 \%$ & 14 & ND \\
\hline 4 & $5.3 \%$ & 14 & 19 \\
\hline 5 & $3.5 \%$ & 14 & 19 \\
\hline 6 & $4.2 \%$ & 14 & 19 \\
\hline 7 & $3.0 \%$ & 15 & 20 \\
\hline 8 & $3.8 \%$ & 16 & 21 \\
\hline 9 & $2.5 \%$ & 16 & 21 \\
\hline 10 & $2.3 \%$ & 19 & 25 \\
\hline pET-1 (no enhancer) & $0.3 \%$ d & $30^{e}$ & ND \\
\hline SV 40 & $6.6 \%$ & 10 & 16 \\
\hline SV7.2 mutant ${ }^{\dagger}$ & $3.1 \%$ & 16 & 20 \\
\hline
\end{tabular}

all DNAs were transfected in linear form (see text).

$\mathrm{b}$ The percentage of $\mathrm{T}$ antigen positive cells was determined by count ing several areas of $0.145 \mathrm{~mm}^{2}$ as described in Banerji et al. (1981) From other experiments with duplicate transfections it is extrapolated that the experimental error in Experiment 1 is about $\pm 0.5 \%$ T antigen positive cells.

" In several other experiments the SV40-HCMV recombinant $\mathrm{C} 4$ lysed the monkey CV1 cells even faster than SV40 (not shown).

${ }^{d}$ All of the positive cells showed dull fluorescence only.

e No lysis after 30 days of observation.

I This SV 40 mutant has generated an enhancer de novo by sequence rearrangements that is about $30 \%$ as active as the SV40 wild-type enhancer (Weber et al., 1984).

ND: not determined.

and $\mathrm{C} 4$ enhance synthesis of correctly initiated $\beta$-globin transcript by at least 2 orders of magnitude, irrespective of orientation. Whereas the "C2 enhancer" (lanes 3,4$)$ is as active as the SV40 enhancer (lane 9), the activity of the "C4 enhancer" is 3 to 5 fold stronger (lanes 5,6 ). Therefore, the HCMV genome bears an enhancer element that is stronger than any other enhancer we have analyzed so far.

\section{The Enhancer Effect Is Obscured by HCMV Promoter Sequences}

In contrast to the orientation independence of the transcriptional enhancing effect exerted by the HCMV sequences from $\mathrm{C} 2$ and $\mathrm{C} 4$, strong polar effects were seen when the Pst I m-fragment of HCMV was inserted downstream of the $\beta$-globin gene. This fragment contains the complete enhancer/promoter region, including the transcriptional start site of the $1.9 \mathrm{~kb}$ IE mRNA (see above). In construct $\mathrm{p} \beta \mathrm{X}-1428$ (Figures $4 \mathrm{~A}$ and $4 \mathrm{C}$, lane 7 ), in which the directions of transcription of the $1.9 \mathrm{~kb}$ IE mRNA and the $\beta$-globin mRNA are opposite each other, almost no enhancing activity on $\beta$-globin transcription could be detected. This is not unexpected because the $\beta$-globin gene is separated from the enhancer by a full-length copy of a bacterial plasmid at its $5^{\prime}$ end and by the strong IE promoter of HCMV at its $3^{\prime}$ end. It has been shown that 
A

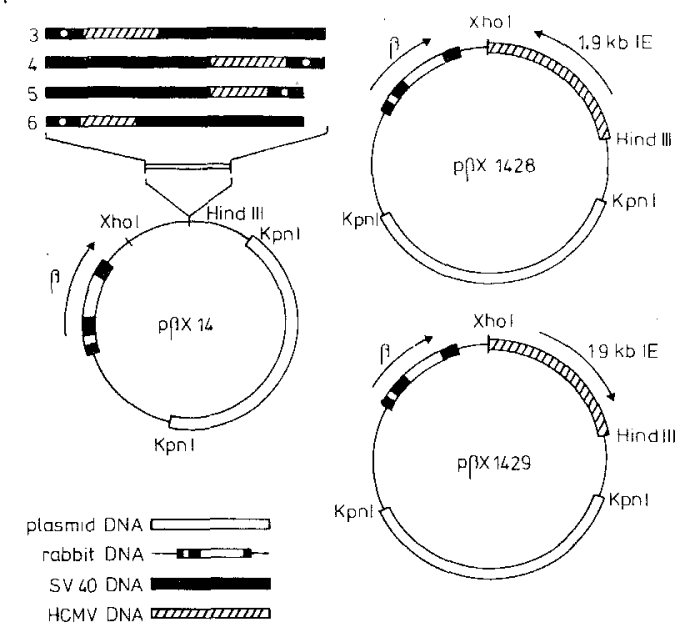

B

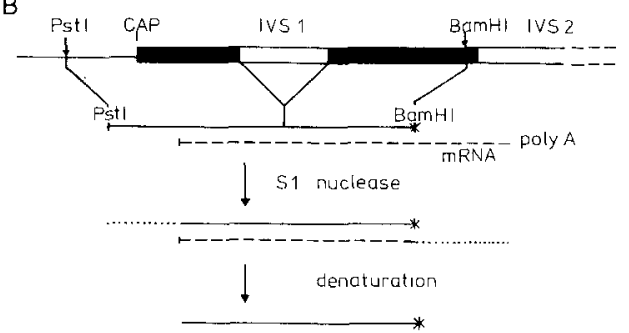

C

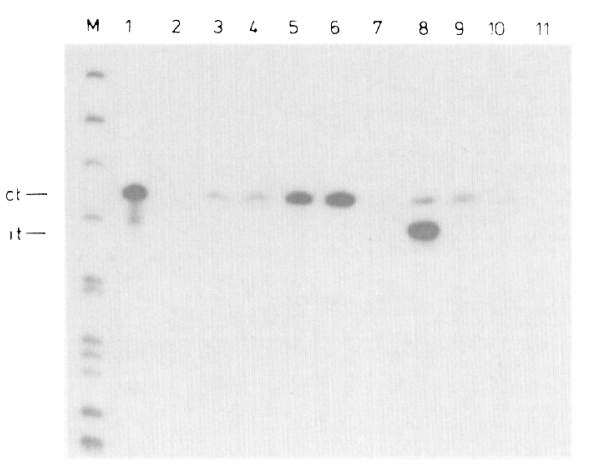

Figure 4. Comparative Analysis of Enhancer Strength, As Measured by S1 Nuclease Assay

(A) Plasmid constructs used for testing enhancer activity of HCMV sequences. Different fragments were inserted downstream of the genomic rabbit $\beta$-globin gene (Maniatis et al., 1978) in clone $\mathrm{p} \beta \times 14$ (a gift from J. Banerii), which is a derivative of $p \beta G X$ (Banerji et al., 1983) containing a Hind III linker at the single Xba I site. The Hind III C-fragments of recombinant viruses $\mathrm{C} 2$ and $\mathrm{C} 4$ were inserted at this Hind III site in either orientation as indicated at the top. Plasmids $\mathrm{p} \beta \mathrm{HC} 22(3)$ and $\mathrm{p} \beta \mathrm{HC} 21$ (4) contain the Hind III C-fragment of $\mathrm{C} 2$; $\mathrm{p} \beta \mathrm{HC} 41$ (5) and $\mathrm{p} \beta \mathrm{HC} 42(6)$, the Hind III $\mathrm{C}$-fragment of $\mathrm{C} 4$. The HCMV sequence within the Hind III C-fragment is represented by a hatched box, and the SV4O origin of replication is indicated.

The Pst I m-segment of HCMV was inserted in both orientations between the Xho I and the Hind III sites of $\mathrm{p} \beta X 14$ via synthetic linkers. In $\rho \beta X 1428$ the $\beta$-globin gene and the dominant IE gene of HCMV are in opposite orientation to each other, in $\rho \beta \times 1429$ in the same orientation respectively.

(B) S1 nuclease mapping scheme. Cytoplasmic RNA (20 $\mu \mathrm{g})$ from transfected HeLa cells was hybridized to an excess of end-labeled $\beta$-globin transcription is severely reduced if the $\beta$-globin gene is separated from an enhancer by plasmid DNA (Banerji et al., 1981; Wasylyk et al., 1983) or by an active promoter (de Villiers et al., 1983; Wasylyk et al., 1983; Kadesch and Berg, 1983). In construct $p \beta X-1429$ the direction of RNA synthesis from the IE promoter of HCMV and the orientation of $\beta$-globin transcription are identical (Figure 4A). After transfection into HeLa cells, correctly initiated $\beta$-globin transcripts were synthesized from $p \beta X 1429$ in amounts about equal to amounts synthesized from a construct ( $p 14511)$ containing the SV40 enhancer in an equivalent position downstream of the $\beta$-globin gene (Figure $4 C$, lane 8 ). In addition, the $S 1$ nuclease analysis revealed a much stronger band, representing a protected single strand of 306 nucleotides. From previous experiments it can be assumed that this shortened protected fragment is formed by aberrant splicing to a splice acceptor sequence at position +48 of the rabbit $\beta$-globin gene (de Villiers and Schaffner, 1981). This suggests that transcription from plasmid $p \beta X 1429$ is initiated from the strong IE promoter of HCMV, and that the IE RNA leader of 121 nucleotides is spliced to the $\beta$-globin transcript at position +48 . This conclusion was supported by Northern blot hybridizations showing that RNA of the corresponding size hybridized identically with HCMV IE DNA and $\beta$-globin DNA probes (data not shown).

In conclusion, it appears that the (proximal) promoter components of HCMV act as an efficient "sink" for transcriptional activity, resulting in a reduction and a polarity of the enhancer effect. In contrast, no such effects were seen with the relatively weak early promoter of SV40 (de Villiers et al., 1983, and Figure 4).

\section{Analysis of Enhancer Function by Deletion Mutagenesis}

Further experiments were undertaken to identify the functionally essential parts of the enhancer region. To this end, small restriction fragments within the enhancer region were deleted. The recombinant viruses $\mathrm{C} 2$ and $\mathrm{C} 4$

DNA probe prepared from a $\beta$-globin gene clone lacking the first intervening sequence (IVS1; Weber et al., 1981; a gift from $\mathrm{H}$. Weber) and labeled at the Bam $\mathrm{HI}$ site. The hybrids were digested with $\mathrm{S1}$ nuclease, denatured, fractionated by polyacrylamide gel electrophoresis in the presence of $8 \mathrm{M}$ urea, and autoradiographed.

(C) S1 nuclease analysis of RNA from HeLa cells transfected with the $\beta$-globin constructs described in (A) and various controls. Lane 1: rabbit reticulocyte mRNA. Lane 2: $\mathrm{p} \beta \times 14$. Lanes 3-6 correspond to numbers 3-6 in (A). Lane 3: $p \beta \mathrm{HC22}$. Lane 4: $\mathrm{p} \beta \mathrm{HC21}$. Lane 5: $\mathrm{p} \beta \mathrm{HC41}$. Lane 6: $p \beta H C 42$. Lane 7: $p \beta \times 1428$. Lane 8: $p \beta \times 1429$. Lane 9: $p 14511$ contains the $196 \mathrm{bp}$ enhancer fragment of SV40 downstream of the rabbit $\beta$-globin gene (a gift from L. Olson). Lane 10: HWT3 (Weber et al., 1984) contains the SV40 Hind III C-fragment downstream of the rabbit $\beta$-globin gene (lane 10 suffered the loss of some material; p14511 and HWT3 are equally active in independent experiments; data not shown). Lane 11: $p \beta G H C \triangle E$ contains the Hind III C-fragment of a reclosed viral enhancer trap DNA, lacking enhancer sequences, downstream of the $\beta$-globin gene (Weber et al., 1984).

$\mathrm{M}$ : end-labeled marker DNA fragments. ct: correct terminus (a 354 nucleotide fragment is protected from $\$ 1$ nuclease digestion by MRNA correctly initiated at the globin gene cap site). it: incorrect terminus, mapping about 48 bp downstream of the globin gene cap site (presumably from splicing of far-upstream transcripts to a pseudoacceptor site at position +48 , see text). 


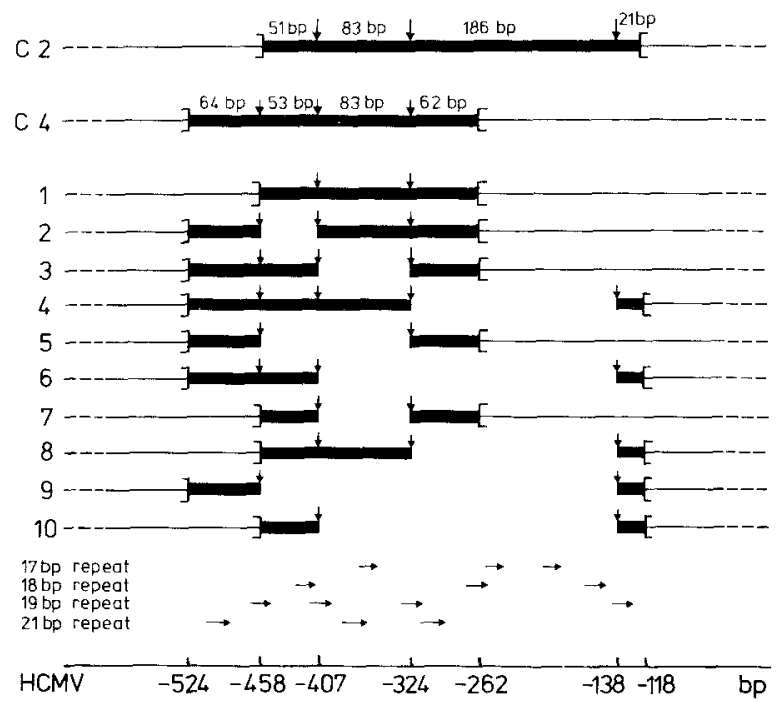

Figure 5. Construction of SV40-HCMV Recombinants with Deletions in the HCMV Enhancer Region

Recombinant viruses $\mathrm{C} 2$ and $\mathrm{C} 4$ (only the enhancer region is represented) were partially digested with Aha II restriction endonuclease (vertical arrows). Purified digestion products were re-ligated in different combinations in order to obtain a set of SV40-HCMV recombinants lacking one or more Aha II fragments from the enhancer region. The length of the Aha Il fragments is indicated, and thus the length of each individual deletion can be calculated. HCMV-DNA is represented by a broad line. The position of the different repeat elements in the HCMV enhancer region and the nucleotide numbers of the deletion endpoints are included. Note that the right-hand junction with SV4O DNA (thin line) is identical for recombinants $1-10$ (SV40 position 301) whereas at the left-hand junction recombinants $2,3,4,5,6$, and 9 lack 25 bp of SV40 DNA relative to recombinants $1,7,8$, and 10 . This is due to a different left-hand junction of recombinant viruses $\mathrm{C} 2$ and $\mathrm{C} 4$ as shown in Figure 1.

were used for construction of a series of such deletion mutants (Figure 5). The restriction enzyme Aha II was convenient for this purpose, as it does not cleave SV40 DNA but cuts within the palindromic $19 \mathrm{bp}$ sequence that is repeated four times in the enhancer region of HCMV (see Figure 3). Partial Aha II digestion products of $\mathrm{C} 2$ and $\mathrm{C} 4$ were re-ligated in different combinations to generate ten SV40-HCMV recombinants (Figure 5). These recombinants were excised from the vector and transfected into $\mathrm{CV} 1$ cells. $\mathrm{T}$ antigen production and virus growth were analyzed because both are dependent on enhancer sequences. The results (Table 1) indicate that relatively small deletions have little or no effect, whereas large deletions reduce $T$ antigen expression and virus growth. Some of the mutants grow as slow as, or slower than, the previously characterized SV40 variant SV7.2, which has an enhancer about $30 \%$ as active as wild-type SV40 (Table 1). From this we conclude that the activity of the HCMV enhancer (which is 3 to 5 fold stronger than the SV40 enhancer, see Figure 4) is reduced to less than $10 \%$ by the extended deletions. However, we had to exclude the possibility that the extended deletion mutants were not viable and that cell lysis was due to late outgrowth of rare variants, e.g. harboring sequence duplications (see also Weber et al., 1984). Since such variants are not visible within the first few days, one series of transfections was stained for $T$ antigen production 2 days after transfection. In CV1 host cells in which viral DNA replicates to high copy numbers $T$ antigen expression levels off as a result of autorepression (Tooze, 1981). Thus T antigen expression is not proportional to enhancer activity in SV40 recombinants with a strong enhancer. For mutants with extended enhancer deletions, however, there is a good correlation between $\mathrm{T}$ antigen fluorescence and virus growth (see Table 1). It is most remarkable that all deletion mutants are viable and thus retain at least the minimum enhancer activity required for viral replication.

\section{Discussion}

\section{The Enhancer Trap}

This study has identified a strong enhancer sequence in the genome of human cytomegalovirus (HCMV) by use of an SV40 enhancer trap (Weber et al., 1984). The SV40 enhancer trap appears particularly useful for the identification of enhancers in the genomes of poorly characterized viruses, because an enhancer can be selected from a large excess of nonenhancing DNA. The procedure has also been used to identify and characterize heterologous enhancer sequences from various other viruses. In independent experiments we have identified and/or further characterized enhancers in the genome of Herpesvirus saimiri (S. Schirm, F. Weber, W. Schaffner, and B. Fleckenstein, unpublished), murine cytomegalovirus (K. DorschHäsler, G. Keil, W. Schaffner, and U. H. Koszinowski, unpublished), Rous sarcoma virus (F. Weber and W. Schaffner, 1985), and hepatitis B virus (A. Tognoni, R. Cattaneo, and $W$. Schaffner, unpublished). Among these strong viral enhancers, the one from HCMV has the highest activity not only in primate cells but also in cell lines from other species, including frog kidney cells; thus it is the strongest enhancer we have found so far.

\section{Regulation of Immediate-Early Transcription}

The HCMV enhancer identified in this study is located upstream of the major viral immediate-early (IE) gene. Its location within the IE region of HCMV strongly suggests that this enhancer directs the initial transcription of the virus; it is in agreement with the findings that early gene transcription of many viruses is dependent on enhancer elements (reviewed in Gluzman and Shenk, 1983; Gruss, 1984; Picard, 1985). However, classical enhancers directing constitutive gene expression in cis, analogous to the elements of small DNA viruses, had not been demonstrated before in the complex genomes of herpesviruses.

Herpesviruses are highly heterogeneous in functional genome organization, resulting in remarkable diversity of their IE transcription units. Some members of the herpes group such as pseudorabies virus or Herpesvirus saimiri possess a single dominant IE gene (Feldman et al., 1982; Bodemer et al., 1984). Other herpesviruses have several IE transcription units. Herpes simplex virus (HSV), the herpesvirus most extensively studied, contains five IE genes. The regulation of IE transcription in HSV exhibits some unique features. The IE genes of HSV are coordinately stimulated in trans by a structural component 
of the virus particle. The regulation is mediated by farupstream sequences of the HSV IE genes, which all share a consensus sequence that seems to be essential for transactivation (Mackem and Roizman, 1982a; Cordingley et al., 1983; Preston et al., 1984; Kristie and Roizman, 1984). Recently an enhancer-like sequence with some host cell preference has been described in the far-upstream region of HSV type 1 IE mRNA 3 ( $\alpha$-gene 4 ). It has been suggested that for IE mRNA 3 the cis-acting enhancer-type sequence might mediate the transactivation (Lang et al., 1984). The activity of the HSV type 1 enhancer-like element is, however, severely reduced or absent when it is inserted downstream of indicator genes (Preston and Tannahill, 1984). This property appears to distinguish the HSV element from canonical enhancers of other viruses. We have compared the sequence of the $\mathrm{HCMV}$ enhancer with the upstream regions of all five HSV IE genes, including the activator element upstream of IE gene 3 (Mackem and Roizman, 1982b; Watson and Vande Woude, 1982; Whitton et al., 1983; Whitton and Clements, 1984). No homology $\geqslant 70 \%$, to any of the repeated sequence motifs in the HCMV enhancer (17 bp, $18 \mathrm{bp}, 19 \mathrm{bp}$, and 21 bp repeats), could be found in the upstream regions of HSV IE genes. The HSV activator consensus motif TAATGARATNC, common to all HSV IE genes and present within the HSV enhancer-like element, is absent from the HCMV enhancer sequence. The sequence dissimilarities may reflect quite different mechanisms of regulation of IE transcription in HSV and HCMV. This is not surprising in the light of the highly diverse biological properties of herpesviruses.

The large genome of HCMV AD169 contains at least four IE genes (Jahn et al., 1984a, 1984b; Wilkinson et al., 1984). Transcription of the dominant IE gene of HCMV AD169 is negatively regulated during later phases of virus replication (Jahn et al., 1984a). Possibly the enhancer/promoter region is suppressed by an IE protein. This hypothesis is compatible with the finding of a dramatic accumulation of IE mRNA in the presence of cycloheximide, an inhibitor of protein synthesis.

\section{What Elements Make Up an Enhancer?}

In spite of some encouraging results (Weiher et al., 1983; Lusky et al., 1983; Hearing and Shenk, 1983; Nordheim and Rich, 1983; Hen et al., 1983), it seems difficult to detect a sequence motif common to all enhancers. Rather, scattered short homologies are shared by subgroups of enhancers, and it appears that several types of sequence motifs can be assorted in many combinations to make up an enhancer (Banerji et al., 1983). Such elements can replace each other, since it is possible to construct enhancers in which any given type of "consensus" motif is missing (Weber et al., 1984; W. Herr and Y. Gluzman, personal communication). It remains to be seen how the various sequence motifs are recognized by one or a few cellular factors. The HCMV enhancer described here is the most striking example of an enhancer harboring several types of sequence elements. In a computer analysis of the 930 bp of HCMV DNA, four groups of directly repeated sequences could be detected, each being represented three to five times. Almost all of these repeat elements of $17 \mathrm{bp}$, $18 \mathrm{bp}, 19 \mathrm{bp}$, and $21 \mathrm{bp}$ length were within the HCMV enhancer region defined by the recombinants $\mathrm{C} 2$ and $\mathrm{C} 4$ (Figure 3). Unlike perfect, abutting repeats in the SV40 enhanceripromoter region, the repeats of the HCMV enhancer are imperfect and are separated by nonrepetitive DNA.

The 17 bp sequence is repeated three times, with $88 \%$ to $94 \%$ fidelity (Figure 3 ). The four 18 bp direct repeats, $78 \%$ to $94 \%$ homologous to the consensus sequence ACTAACGGGACTTTCCAA, are remarkable, since they share an 11 bp homology with the 72 bp repeat of SV40 (nucleotides 164-174 and 236-246). This 11 bp homology encompasses the motif TGGAAAT (Weiher et al., 1983) in the opposite strand and is perfectly conserved in two of the $18 \mathrm{bp} \mathrm{HCMV}$ repeats. Although this element may contribute to the enhancer function, deletion mutagenesis has shown that it is not essential for $T$ antigen expression and virus growth of the SV4O-HCMV recombinants. Mu$\operatorname{tant} 9$ does not retain any of the 18 bp elements, and mutants 2 and 5 retain only a truncated copy (Table 1 and Figure 5).

A sequence of $19 \mathrm{bp}$ that is repeated five times, with $84 \%$ to $89 \%$ fidelity, itself contains an inverted repeat ("palindrome"; Figure 3). As a consequence, putative stem-loop structures could form between all of the $19 \mathrm{bp}$ repeat elements. The lengths of the stems (containing the $19 \mathrm{bp}$ repeats, see above) range from $18 \mathrm{bp}$ to $26 \mathrm{bp}$, with base pairing that is $85 \%$ to $90 \%$ correct. This 19 bp repeat is conserved in evolution, as an identical sequence is repeated in the simian cytomegalovirus strain Colburn (K.-T. Jeang and G. Hayward, personal communication). Because some of our deletion mutants of the HCMV enhancer (5 and 9 in Table 1 and Figure 5) retain only one copy of this $19 \mathrm{bp}$ palindromic sequence, stem-loop formation can be ruled out as a requirement for enhancer activity. It will be interesting to see whether or not enhancer activity is severely affected by elimination of this motif. However, as discussed above, enhancer motifs can apparently substitute for each other; therefore, elimination of the 19 bp repeat may only be critical in a severely truncated "minimal" enhancer.

Another repeat element of 21 bp length (Figure 3 ) is reiterated three times, with $81 \%$ to $100 \%$ fidelity, and contains the G/C-rich hexanucleotide CCCGCC. This motif and the related sequence CCGCCC are present within the HCMV enhancer sequence in four copies. In addition, two CCGCCC motifs are present as an inverted repeat upstream of the capping site at positions -52 to -57 , and -71 to -76 (Figure 3). In herpes simplex virus, CCGCCC motifs are involved in the modulation of IE gene expression (Kristie and Roizman, 1984; Preston et al., 1984) and are also essential promoter components of the thymidine kinase gene (McKnight et al., 1984). In SV4O, the CCGCCC sequence is present within the $21 \mathrm{bp}$ repeats of the early promoter (Everett et al., 1983) and is known to bind the transcription factor Sp1 (Gidoni et al., 1984).

Direct repeat structures have been found in many enhancers, and duplications generally increase enhancer activity (Weber et al., 1984; de Villiers et al., 1983, 1984). 
The fact that different subsets of the HCMV enhancer region can independently substitute for the SV40 enhancer may indicate that the strong enhancer sequence of HCMV has arisen through amplification and subsequent diversification of a set of original elements. The various imperfect repeat motifs separated from each other by nonrepetitive DNA may be conserved units of such amplification processes. This would explain the inability of extended deletions to eliminate enhancer function, as well as why the relatively long enhancer of HCMV is the strongest enhancer identified thus far.

\section{Experimental Procedures}

\section{Enhancer Trap Assay}

Cell culture, transfection, and analysis of viral DNA have been described (Weber et al., 1984).

\section{Construction of Recombinant DNA Clones}

For construction of plasmids $p \beta \times 1428$ and $p \beta X 1429$, the Pst I m-fragment of HCMV was cloned in both orientations in pUC8 (Vieira and Messing, 1982), excised as Hind III-Sal I fragments, and recloned between the Hind III and Xho I sites of $p \beta X 14$. For construction of the recombinant viruses carrying deletions in the enhancer region, recombinant viruses $\mathrm{C} 2$ and $\mathrm{C} 4$, purified from the plasmid vector, were subjected to partial digestion with Aha II, and the partial digestion products were isolated. Appropriate combinations of early and late regions of the $\mathrm{C} 2$ and $\mathrm{C} 4$ viral DNAs were re-ligated individually with phosphatase-treated pUC8 plasmid in three-component ligations.

\section{Analysis of Gene Expression}

S1 nuclease analysis was performed as described (Weaver and Weissmann, 1979; Rusconi and Schaffner, 1981). Isolation of HCMV IE RNA and Northern blot hybridizations have been described previously (Jahn et al., 1984a). Analysis of SV40 T antigen production by immunofluorescence was performed as described earlier (Banerji et al., 1981, 1983).

\section{Acknowledgments}

This work was supported by Deutsche Forschungsgemeinschaft, Schwerpunkt Viruspersistenz, the Swiss National Research Foundation, and the Kanton of Zürich. Vive thank Bernd Traupe and Ingrid Müller for technical assistance, Wolfgang Rössler for photographic work, Sandor Suhai for help with computer analysis of DNA sequences, A. Grässmann (Berlin) for antibodies against SV40 V antigen, and $F$. A. Anderer and B. Krafczyk (Tübingen) for antibodies against SV40 T antigen. We are grateful to Jean deVilliers, Thomas Gerster, Didier Picard, and Sandro Rusconi for technical advice and helpful discussions, and to Greg Gilmartin, Dani Schümperli, Maria Jasin, Günther Schütz, and Max Birnstiel for critical reading of the manuscript.

The costs of publication of this article were defrayed in part by the payment of page charges. This article must therefore be hereby marked "advertisement" in accordance with 18 U.S.C. Section 1734 solely to indicate this fact.

Received October 26, 1984; revised March 6, 1985

\section{References}

Banerji, J., Rusconi, S., and Schaffner, W. (1981). Expression of a $\beta$-globin gene is enhanced by remote SV40 DNA sequences. Cell 27, 299-308.

Banerji, J., Olson, L., and Schaffner, W. (1983). A lymphocyte-specific cellular enhancer is located downstream of the joining region in immunoglobin heavy chain genes. Cell 33, 729-740.

Benoist, C., and Chambon, P. (1981). In vivo sequence requirements of the SV40 early promoter region. Nature 290, 304-310.

Bodemer, W., Knust, E., Angermüller, S., and Fleckenstein, B. (1984).
Immediate-early transcription of Herpesvirus saimiri. J. Virol., 51, 452-457.

Contreras, R., Gheysen, D., Knowland, J., van de Voorde, A., and Fiers, $W$. (1982). Evidence for the direct involvement of DNA replication origin in synthesis of late SV40 RNA. Nature 300, 500-505.

Cordingiey, M. G., Campbell, E. M., and Preston, C. M. (1983). Functional analysis of a herpes simplex virus type 1 promoter: identification of far-upstream regulatory sequences. Nucl. Acids Res. 11, 2347-2365. DeMarchi, J. M. (1981). Human cytomegalovirus DNA: restriction enzyme cleavage maps and map locations for immediate-early, early, and late RNAs. Virology 114, 23-38.

de Villiers, J., and Schaffner, W. (1981). A small segment of polyoma virus DNA enhances the expression of a cloned $\beta$-globin gene over a distance of 1400 base pairs. Nucl. Acids Res. 9, 6251-6264.

de Villiers, J., Olson, L., Tyndall, C., and Schaffner, W. (1982). Transcriptional "enhancers" from SV40 and polyoma virus show a cell type preference. Nucl. Acids Res. 10, 7965-7976.

de Villiers, J., Olson, L., Banerji, J., and Schaffner, W. (1983). Analysis of the transcriptional enhancer effect. In Cold Spring Harbor Symposia on Quantitative Biology, Vol. XLVII. (Cold Spring Harbor, New York: Cold Spring Harbor Laboratory), pp. 911-919.

de Villiers, J., Schaffner, W., Tyndall, C., Lupton, S., and Kamen, R. (1984). Polyoma virus DNA replication requires an enhancer. Nature $312,242-246$.

Ebeling, A., Keil, G., Nowak, B., Fleckenstein, B., Berthelot, N., and Sheldrick, P. (1983). Genome structure and virion polypeptides of the primate herpesvirus Herpesvirus aotus types 1 and 3 : comparison with human cytomegalovirus. J. Virol. 45, 715-726.

Everett, R. D., Baty, D., and Chambon, P. (1983). The repeated GC-rich motifs upstream from the TATA box are important elements of the SV40 early promoter. Nucl. Acids Res. 11, 2447-2464.

Feldman, L. T., DeMarchi, J. M., Ben-Porat, T., and Kaplan, A. S. (1982). Control of abundance of immediate-early mRNA in herpesvirus (pseudorabies)-infected cells. Virology 116, 250-263.

Fleckenstein, B., Mülter, I., and Collins, J. (1982). Cloning of the complete human cytomegalovirus genome in cosmids. Gene 18, 39-46. Fried, M., Griffiths, M., Davies, B., Bjursell, G., LaMantia, G., and Lania, L. (1983). Isolation of cellular DNA sequences that allow expression of adjacent genes. Proc. Natl. Acad. Sci. USA 80, 2117-2121.

Fromm, M., and Berg, P. (1982). Deletion mapping of DNA required for SV40 early region promoter function in vivo. J. Mol. Appl. Genet. 1 457-481.

Gidoni, D., Dynan, W. S., and Tijan, R. (1984). Multiple specific contacts between a mammalian transcription factor and its cognate promoters. Nature 312, 409-413.

Gillies, S. D., Morrison, S. L., Oi, V. T., and Tonegawa, S. (1983). A tissue-specific transcription enhancer element is located in the major intron of a rearranged immunoglobulin heavy chain gene. Cell 38 , 717-725.

Gluzman, Y., and Shenk, T., eds. (1983). Enhancers and Eukaryotic Gene Expression. (Cold Spring Harbor, New York: Cold Spring Harbor Laboratory).

Greenaway, P. J., Oram, J. D., Downing, R. G., and Patel, K. (1982). Human cytomegalovirus DNA: BamHi, EcoRI and Pstl restriction endonuclease cleavage maps. Gene 18, 355-360.

Gruss, P. (1984). Eucaryotic enhancers. DNA 3, 1-5.

Gruss, P., Dhar, R., and Khoury, G. (1981). Simian virus 40 repeated sequences as an element of the early promoter. Proc. Natl. Acad. Sci. USA 78, 943-947.

Hartzelf, S. W., Yamaguchi, J., and Subramanian, K. N. (1983). SV40 deletion mutants lacking the 21-bp repeated sequences are viable, but have noncomplementable deficiencies. Nucl. Acids Res. 11, 1601-1616.

Hearing, P., and Shenk, T. (1983). The adenovirus type 5 E1A transcriptional control region contains a duplicated enhancer element. Cell 33 , 695-703.

Hen, R., Borelli, E., Sarrone-Corsi, P., and Chambon, P. (1983). An 
enhancer element is located 340 base pairs upstream from the adenovirus-2 E1A capsite. Nucl. Acids Res. 11, 8748-8760.

Jahn, G., Knust, E., Schmolla, H., Sarre, T., Nelson, J. A., McDougall, J. K., and Fleckenstein, B. (1984a). Predominant immediate-early tran scripts of human cytomegalovirus AD 169. J. Virol. 49, 363-370.

Jahn, G., Nelson, J. A., Plachter, B., McDougall, J. K., and Fleckenstein, B. (1984b). Transcription of a human cytomegalovirus DNA region which is capable of transforming rodent cells. In Herpesvirus, $F$. Rapp, ed. (New York: Alan A. Liss, Inc.), pp. 455-463.

Kadesch, T. R., and Berg, P. (1983). Effects of the position of the 72 bp enhancer segment on transcription from the SV40 early region promoter. In Enhancers and Eukaryotic Gene Expression, Y. Gluzman and T. Shenk, eds. (Cold Spring Harbor, New York: Cold Spring Harbor Laboratory), pp. 21-27.

Kristie, T. M., and Roizman, B. (1984). Separation of sequences defining basal expression from those conferring $\alpha$ gene recognition within the regulatory domains of herpes simplex virus $1 \alpha$ genes. Proc. Natl. Acad. Sci. USA 81, 4065-4069.

LaFemina, R. L., and Hayward, G. S. (1980). Structural organization of the DNA molecules from human cytomegalovirus. In Animal Virus Genetics, R. Jaenisch, B. Fields, and C. F. Fox, eds. (New York: Academic Press), pp. 39-55.

Laimins, L. A., Khoury, G., Gorman, C., Howard, B., and Gruss, P. (1982). Host-specific activation of transcription by tandem repeats from simian virus 40 and Moloney murine sarcoma virus. Proc. Natl. Acad. Sci. USA $79,6453-6457$

Lang, J. C., Spandidos, D. A., and Wilkie, N. M. (1984). Transcriptiona regulation of a herpes simplex virus immediate early gene is mediated through an enhancer-type sequence. EMBO J. 3, 389-395.

Levinson, B., Khoury, G., Vande Woude, G. V., and Gruss, P. (1982) Activation of SV40 genome by 72 base pair tandem repeats of Moloney sarcoma virus. Nature 295, 568-572.

Lin, F.-L., Sperle, K., and Sternberg, N. (1984). Model for homologous recombination during transfer of DNA into mouse $L$ cells: role for DNA ends in the recombination process. Mol. Cell. Biol. 4, 1020-1034.

Lusky, M., Berg, L., Weiher, H., and Botchan, M. (1983). Bovine papilloma virus contains an activator of gene expression at the distal end of the early transcription unit. Mol. Cell. Biol. 3, 1108-1122.

Mackem, S., and Roizman, B. (1982a). Differentiation between the promoter and regulator regions of herpes simplex virus 1: the functional domains and sequence of a movable $\alpha$ regulator. Proc. Natl. Acad. Sci. USA $79,4917-4921$

Mackem, S., and Roizman, B. (1982b). Structural features of the herpes simplex virus $\alpha$ gene 4,0 , and 27 promoter-regulatory sequences which confer $\alpha$-regulation on chimeric thymidine kinase genes. J. Virol. $44,939-949$

Maniatis, T., Hardison, R. C., Lacy, E., Lauer, J., O'Connell, C., Quon, D., Sim, G. K., and Efstratiadis, A. (1978). The isolation of structural genes from libraries of eucaryotic DNA. Cell 15, 687-701.

McDonough, S. H., and Spector, D. H. (1983). Transcription in human fibroblasts permissively infected by human cytomegalovirus strain AD169. Virology 125, 31-46.

McKnight, S. L., Kingsbury, R. C., Spence, A., and Smith, M. (1984) The distal transcription signals of the herpesvirus tk gene share a common hexanucleotide control sequence. Cell 37, 253-262.

Moreau, P., Hen, R., Wasylyk, B., Everett, R., Gau, M. P., and Chambon, $P$. (1981). The SV40 72 base repair repeat has a striking effect on gene expression both in SV40 and other chimeric recombinants. Nucl. Acids Res., 9, 6047-6068

Mount, S. M. (1982). A catalogue of splice junction sequences. Nucl. Acids Res. 10, 459-472.

Neuberger, M. S. (1983). Expression and regulation of immunoglobulin heavy chain gene transfected into lymphoid cells. EMBO J. 2, $1373-1378$

Neuhaus, G., Neuhaus-Url, G., Gruss, P., and Schweiger, H.-G. (1984) Enhancer-controlled expression of the simian virus $40 \mathrm{~T}$-antigen in the green alga Acetabularia. EMBO J. 3, 2169-2172.
Nordheim, A., and Rich, A. (1983). Negative supercoiled simian virus 40 DNA contains Z-DNA segments within transcriptional enhancer sequences. Nature 303, 674-679.

Picard, D. (1985). Viral and cellular transcription enhancers. Oxford Surveys on Eukaryotic Genes, Vol. 2, N. Maclean, ed. (Oxford: Oxford University Press), in press.

Picard, D., and Schaffner, W. (1984). A lymphocyte-specific enhancer in the mouse immunoglobulin kappa gene. Nature 307, 80-82.

Preston, C. M., and Tannahill, D. (1984). Effects of orientation and position on the activity of a herpes simplex virus immediate early gene farupstream region. Virology 137, 439-444.

Preston, C. M., Cordingley, M. G., and Stow, N. D. (1984). Analysis of DNA sequences which regulate the transcription of a herpes simplex virus immediate early gene. J. Virol. 50, 708-711.

Queen, C., and Baltimore, D. (1983). Immunoglobulin gene transcription is activated by downstream sequence elements. Cell $33,741-748$.

Rusconi, S., and Schaffner, W. (1981). Transformation of frog embryos with a rabbit $\beta$-globin gene. Proc. Natl. Acad. Sci. USA 78, 5051-5055. Stagno, S., Pass, R. F., Dworsky, M. E., Henderson, R. E., Moore E. G., Walton, P. D. and Alford, C. A. (1982). Congenital cytomegalovirus infection: the relative importance of primary and recurrent maternal infection. N. Engl. J. Med. 306, 945-949.

Stenberg, R. M., Thomsen, D. R., and Stinski, M. F. (1984). Structural analysis of the major immediate early gene of human cytomegalovirus. J. Virol. 49, 190-\$99.

Stinski, M. F. (1983). Molecular biology of cytomegaloviruses. In The Herpesviruses, Vol. 2, B. Roizman, ed. (New York: Plenum Press), pp. $67-113$

Stinski, M. F., Thomsen, D. R., Stenberg, R. M., and Goldstein, L. C (1983). Organization and expression of the immediate early genes of human cytomegalovirus. J. Virol. 46, 1-14.

Thomsen, D. R., Stenberg, R. M., Goins, W. F., and Stinski, M. F. (1984). Promoter-regulatory region of the major immediate early gene of human cytomegalovirus. Proc. Natl. Acad. Sci. USA 81, pp. $659-663$

Tooze, J., ed. (1981). DNA Tumor Viruses. (Cold Spring Harbor, New York: Cold Spring Harbor Laboratory).

Tyndall, C., La Mantia, G., Thacker, C. M., Favaloro, J., and Kamen, R (1981). A region of the polyoma virus genome between the replication origin and late protein coding sequences is required in cis for both early gene expression and viral DNA replication. Nucl. Acids Res. 9 $6231-6250$

Vieira, J., and Messing, J. (1982). The pUC plasmids, an M13mp7derived system for insertion mutagenesis and sequencing with syn thetic universal primers. Gene 19, 259-268.

Wasylyk, B., Wasylyk, C., Augereau, P., and Chambon, P. (1983). The SV40 72 bp repeat preferentially potentiates transcription starting from proximal natural or substitute promoter elements. Cell 32, 503-514.

Wathen, M. W., and Stinski, M. F. (1982). Temporal patterns of human cytomegalovirus transcription: mapping the viral RNAs synthesized at immediate early, early, and late times after infection. J. Virol. 41, 462-477.

Watson, R. J., and Vande Woude, G. F. (1982). DNA sequence of an immediate-early gene (IE mRNA-5) of herpes simplex virus 1. Nucl. Acids Res. 10, 979-991.

Weaver, R. F, and Weissmann, C. (1979). Mapping of an RNA by a modification of the Berk-Sharp procedure: the 5 'termini of $15 \mathrm{~S} \beta$-globin mRNA precursor and mature 10S $\beta$-globin mRNA have identical map coordinates. Nucl. Acids Res. 7, 1175-1193.

Weber, F., and Schaffner, W. (1985). Enhancer activity correłates with the oncogenic potential of avian retroviruses. EMBO J., in press.

Weber, F., de Villiers, J., and Schaffner, W. (1984). An SV40 "enhancer trap" incorporates exogenous enhancers or generates enhancers from its own sequences. Cell 36, 983-992.

Weber, H., Dierks, P., Meyer, F., van Ooyen, A., Dobkin, C., Abrescia P., Kappeler, M., Meyhack, B., Zeltner, A., Mullen, E. E., and Weissmann, C. (1981). Modification of the rabbit chromosomal $\beta$-globin gene 
by restructuring and site-directed mutagenesis. ICN-UCLA Symp. Mol Cell. Biol. 33, 367.

Weiher, H., König, M., and Gruss, P. (1983). Multiple point mutations affecting the simian virus 40 enhancer. Science 219, 626-631.

Weller, T. H. (1971). The cytomegaloviruses: ubiquitous agents with protean clinical manifestation. N. Engl. J. Med. 285, 203-213; 267-274.

Whitton, J. L., and Clements, J. B. (1984). Replication origins and a sequence involved in coordinate induction of the immediate-early gene family are conserved in a intergenic region of herpes simplex virus. Nucl. Acids Res. 12, 2061-2079.

Whitton, J. L., Rixon, F. J., Easton, A. J., and Clements, J. B. (1983). Immediate-early mRNA A-2 of herpes simplex virus types 1 and 2 is unspliced: conserved sequences around the $5^{\prime}$ and $3^{\prime}$ termini correspond to transcription regulatory signals. Nucl. Acids Res. 11 , 6271-6287.

Wilkinson, G. W. G., Akrigg, A., and Greenaway, P. J. (1984). Transcription of the immediate early genes of human cytomegalovirus strain AD169. Virus Res. 1, 101-116. 